\title{
Imponderable Music: Using infrasonic frequencies as a stimulus for haptic perception within installation based work
}

\author{
Justine Flynn \\ University of Central Lancashire \\ United Kingdom \\ JFlynn@Uclan.ac.uk \\ www.myspace.com/theimponderablebomb
}

\begin{abstract}
Justine Flynn is an audio/visual artist who has been installing work, writing contemporary music and directing contemporary performance since 1997 and is currently researching Imponderable Sound: at UCLan.
\end{abstract}

Imponderable Sound is sonic art that is inaudible and is composed by using only infrasonic frequencies or infrasound. Infrasound (sound that operates below the average hearing spectrum) is a vibration that can be detected through the body via the bones, skin and internal organs and is then interpreted by the brain in the same way that music is interpreted when perceived by the ears. This means that by using infrasound as a means of physical vibration, the body can be affected through its tactile sensory receptors to add a new dimension to music by the addition of 'touch'.

Imponderable Sound One -- 'Pipe Dream'

This installation consists of over 5.4 metres of tubing sculpted and activated electronically to emit an infrasonic frequency.

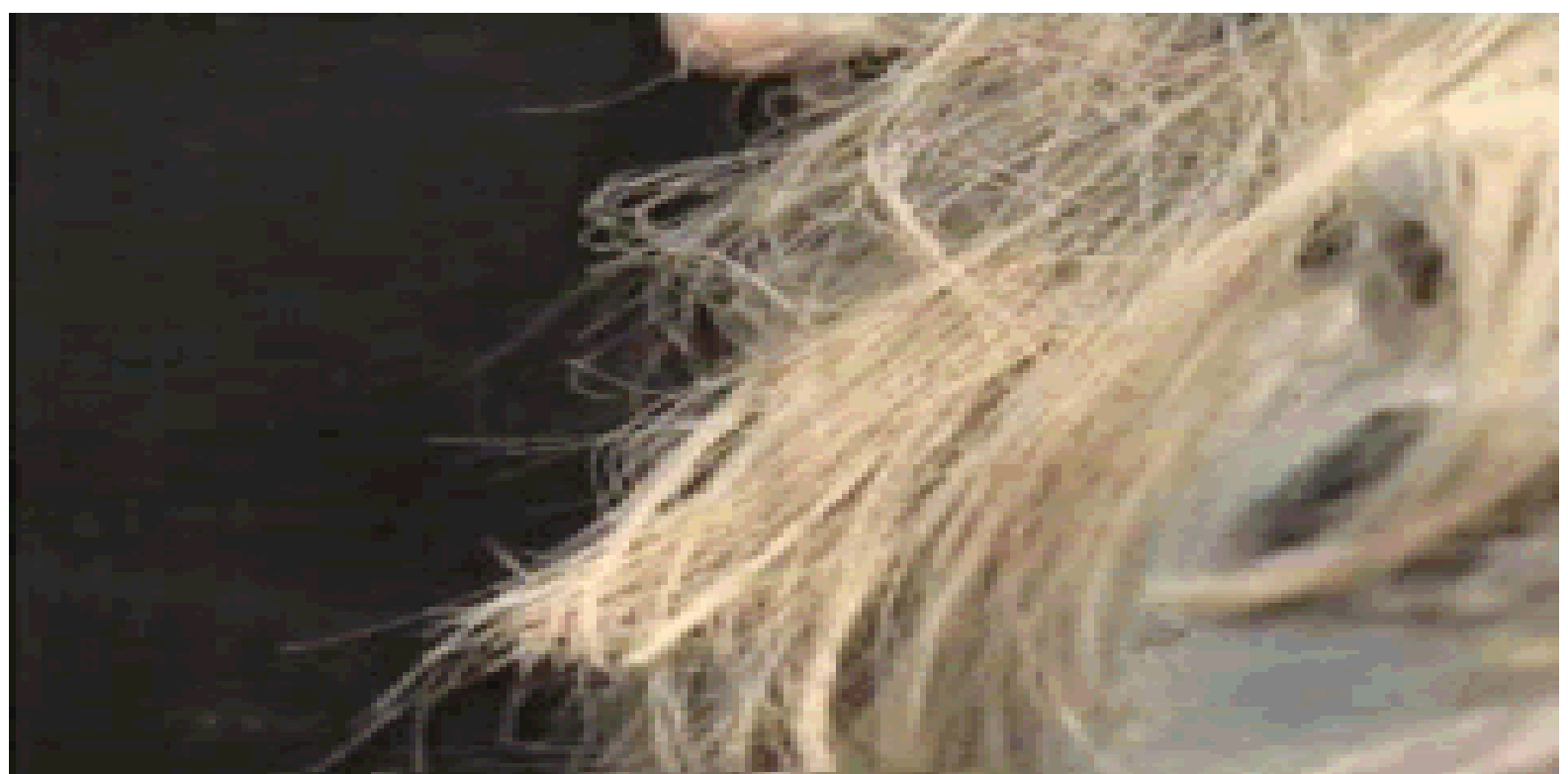

